\title{
Type D personality and acceptance of illness in people with inflammatory bowel diseases. Mediating role of self-esteem
}

\author{
Olga Graf (1D ${ }^{A, B, C, D, E, F}$, Beata A. Urbańska (DD ${ }^{B, C, D, E}$, Patrycja Uram (D) ${ }^{A, C, E, F}$ \\ Institute of Psychology, Polish Academy of Sciences, Warsaw, Poland
}

\section{BACKGROUND}

Type D personality is analyzed more and more frequently in the context of various chronic illnesses, including bowel diseases. Acceptance of illness is affected by many factors that facilitate adaptation to the difficulties and limitations and support the healing process. One of those factors may be self-esteem.

\section{PARTICIPANTS AND PROCEDURE}

One hundred fifty-nine individuals, aged 18 to 65 , participated in the study. $67 \%(n=107)$ stated that they have ulcerative colitis (UC), and the remaining $33 \%(n=52)$ reported suffering from Crohn's disease (CD). The following measurement tools were used: Rosenberg Self-Esteem Scale (SES), Acceptance of Illness Scale (AIS), and Personality Type D Scale (D14).

\section{RESULTS}

The conducted analyses revealed significant correlations between all studied elements. Self-esteem was proven to be a full mediator in relations between one of the dimensions of type D personality, negative affectivity, as well as between both dimensions of type D personality (negative affectivity and social inhibition) and acceptance of illness in individuals with bowel diseases. However, mediation analysis did not confirm that self-esteem is a mediator between social inhibition and acceptance of illness.

\section{CONCLUSIONS}

The results show that self-esteem is, for an individual, an essential resource in coping with an illness and adjusting to it. Therefore, providing patient support in the scope of reinforcing self-esteem may prove to be one of the key elements affecting illness acceptance.

KEY WORDS

self-esteem; acceptance of illness; type D personality

Corresponding Author - Olga Graf, Institute of Psychology, Polish Academy of Sciences, 1 Jaracza Str., 00-378 Warsaw, Poland, e-mail: olga.graf@sd.psych.pan.pl

AUthors' Contribution - A: Study design - B: Data collection - C: Statistical analysis - D: Data interpretation .

E: Manuscript preparation · F: Literature search · G: Funds collection

to Cite this ARTicle - Graf, O., Urbańska, B. A., \& Uram, P. (2021). Type D personality and acceptance of illness in people with inflammatory bowel diseases. Mediating role of self-esteem. Current Issues in Personality Psychology, 9(3), 205-214.

RECEIVED 26.11.2020 • REVIEWED 14.02.2021 · ACCEPTED 05.05.2021 · PUBLISHED 14.06.2021 


\section{BACKGROUND}

Researchers often investigate how individuals with chronic diseases function, including how they accept their illness. Acceptance means understanding and adopting the limitations brought on by the ailment (Basińska \& Andruszkiewicz, 2016; Krajewski et al., 2018; Telford et al., 2006). It is an important element of how patients function, and it helps them to adapt to the new situation - living with their chronic illness (Cybulski et al., 2017). Acceptance of illness is affected by many factors that facilitate adaptation to the difficulties and limitations and support the healing process.

A study by Basińska and Andruszkiewicz (2016) showed that the acceptance of illness level is negatively correlated with the intensity of type D personality traits in the studied individuals. However, the study did not confirm any correlations between the level of acceptance of illness and gender or level of education of the participants (Basińska \& Andruszkiewicz, 2016).

For a few years now, we have seen an increase in researchers' interest in stress personality, also known as type D personality, designated as one of the risk factors for developing somatic illnesses (Basińska \& Andruszkiewicz, 2016). Type D personality shows significance in how an individual perceives situations as causing stress; it also affects the methods employed to deal with stress. Type D is a specific type of personality, the most recent one to be identified in the literature - by the clinical psychologist Johan Denollet - and is composed of two dimensions: negative affectivity and social inhibition. The first dimension expresses an individual's tendency to display exceedingly negative emotions such as anger, anxiety, and irritation, thus showing similarity to neuroticism. The second dimension is characterized by limiting social interactions, thus creating distance from others, inhibiting oneself from expressing negative emotions and appropriate behaviors, showing similarity to introversion (Ogińska-Bulik, 2009). Individuals displaying type D personality are characterized by a tendency to experience negative emotions and even develop depression. Moreover, they are more prone to feel tension and lack of sense of security. They are also characterized by a pessimistic outlook and a tendency to overly worry, as well as by low life satisfaction (Juczyński \& Ogińska-Bulik, 2012).

Although initially the studies analyzing type D personality were conducted on patients with heart diseases, more and more frequently, the studies are expanded to include patients suffering from various chronic illnesses, including bowel diseases (Morys et al., 2016; Sajadinejad et al., 2012). Chronically ill individuals with type $\mathrm{D}$ personality experience negative emotional states, such as fear, depression, or hostility, more often than others. They have a lower quality of life and an increased tendency to adopt risky behav- iors. They are also more strongly affected by external stressors (Basińska \& Andruszkiewicz, 2016).

A study conducted in 2012 on linking the NEO-PI-R and type D personality profiles with patients' quality of life with bowel illnesses showed that type D personality occurrence was higher in the patients than in the control group. Moreover, the quality of life of patients with type D personality was lower than that of patients without type D personality. It is worth adding that type $\mathrm{D}$ personality was a better predictor of the patients' quality of life than NEO-PI-R measurements (Sajadinejad et al., 2012). Similar data about the tendency of individuals with inflammatory bowel disease to have type $\mathrm{D}$ personality were obtained in a study conducted by Morys et al. (2016).

Acceptance of illness is also related to self-esteem. By reinforcing mental health, self-esteem protects individuals from, among other things, fear, depression, and effects of stressors by fulfilling an adaptational function. It has great importance for mental comfort and, by extension, for acceptance of illness, with which self-esteem is positively correlated (Juczyński, 2012). The theory states that type D personality, on the other hand, is correlated negatively with self-esteem (Juczyński \& Ogińska-Bulik, 2012). This was confirmed, for example, by studies conducted by Huis in 't Veld et al. (2011).

Previous data on self-esteem show that it may be an important element in coping with chronic illnesses (Hogg \& Vaughan, 2011). Results of studies show that high self-esteem in chronic illnesses safeguards against a tendency towards depression (Bisschop et al., 2004), negative emotions and intensified symptoms of stress (Juth et al., 2008). It plays an important role in coping with the illness, which is a key factor in its acceptance (Greenley et al., 2010). Therefore, taking into account the results of previous studies that revealed the proclivity of patients with bowel disease to display tendencies towards traits characteristic of type D personality (stress personality), self-esteem should be a protective factor in coping with and accepting the illness. However, it is worth adding that in the case of adults who suffer from bowel diseases, studies on self-esteem are limited. The relatively high stigmatization (Taft et al., 2009) associated with those diseases, and related to the experienced symptoms and the frequent dissatisfaction with the body image of the patients (McDermott et al., 2015), is often linked with low self-esteem.

Inflammatory bowel diseases are chronic immunological illnesses with varied courses. They are characterized by inflammation of the organism - most often the bowels (Moreno-Jiménez et al., 2007). Inflammatory diseases of the bowels include primarily ulcerative colitis (CU) and Crohn's disease (CD) (Kiebles et al., 2010; Pellissier et al., 2010). The etiology of inflammatory bowel illnesses is unknown, but probable causes include unhealthy eating habits, using drugs, and lack 
of physical activity. Additionally, everyday rush and stress accompanying everyday life are suggested contributors (Morys et al., 2016).

Ulcerative colitis is characterized by an inflammation localized exclusively within the large intestine. Crohn's disease may affect any portion of the digestive system, from the oral cavity to the anus. Bowel diseases are incurable, which means they fall into a remission-relapse pattern, with various durations of those stages (Sajadinejad et al., 2012). They are characterized by periods when the disease and its symptoms, such as emesis, diarrhea, and stomach pains, are very intense and debilitating, both physically and mentally, and periods of remission, when the intensity of symptoms decreases (Polak, 2020). The somatic ailments the patients experience, the chronic, relapsing character of the disease, and various complications that often require surgical procedures, bear several negative consequences for mental health, such as social withdrawal, intensification of anxiety and depression, apathy, the feeling of loneliness, or stigmatization, which can, in turn, result in lack of acceptance of the illness. While bowel disease cases are increasing throughout the world, it is the highly developed countries where the largest increases in frequencies are occurring. Furthermore, ulcerative colitis and Crohn's disease more and more often affect young people. The onset of the disease is usually in adolescence/early adulthood (15-35 years) (Byron et al., 2020; Polak et al., 2020).

That stress aspect, and tendency towards stress personality, deserve special attention; it is believed that chronic stress, prevalent mainly in western civilizations, may be an important factor for progression and the course of inflammations in chronic diseases (Triantafillidis et al., 2013). The results of studies show that stress is a determinant factor for the course of the disease in people with bowel diseases (Maunder \& Levenstein, 2008; Sgambato et al., 2017). Thus, studies often focus on assessing stress personality in individuals with bowel diseases (Morys et al., 2016; Sajadinejad et al., 2012). One potential explanation why patients with bowel diseases feel stress refers to the biopsychosocial model. It assumes that health may affect our mind, but the mind can affect how healthy we are or how well we cope with diseases. Therefore, even if stress itself does not cause disease, it may cause intensification of physiological symptoms characteristic for the bowel disease course, leading to intensification of impulsiveness and irritability. On the other hand, experiencing symptoms in bowel disease is often linked with significant mental discomfort and the feeling of embarrassment when the symptoms intensify. The possibility of experiencing stomach pains, emesis, and uncontrolled diarrhea may cause an individual to feel more tension and cause them to feel stress (Goodhand et al., 2012; Goodhand \& Rampton, 2008).
In the model proposed by Moss-Morris (2013) on coping with chronic illness, special importance is given to cognitive factors, such as acceptance of illness, finding positives in the course of the disease, and the ability to handle problems and difficulties resulting from the disease. Thus, referring to the above model, the purpose of our study was to ascertain whether self-esteem acts as a mediator between stress personality and acceptance of illness in individuals suffering from inflammatory bowel disease (Polak et al., 2020).

\section{PARTICIPANTS AND PROCEDURE}

\section{PARTICIPANTS}

One hundred and fifty-nine individuals in total, aged 18 to 65 , participated in the study. Sixty-five percent of participants were women. Participants were differentiated according to the illness. Sixty-seven percent $(n=107)$ of all studied individuals stated that they had ulcerative colitis and thirty-three percent $(n=52)$ reported suffering from Crohn's disease. Detailed information concerning participants is presented in Table 1. Sociodemographic data did not statistically significantly affect the evaluated variables.

The study has been accepted by the Ethics Committee of the Institute of Psychology, Polish Academy of Sciences. Participants' recruitment was conducted electronically, using the Google Forms platform. The study was voluntary and anonymous. Before participation, each individual received information on the purpose of the study and its procedure and gave their informed consent to participate. The procedure involved completing surveys on self-esteem, type D personality, illness acceptance, and a sociodemographic questionnaire prepared for this study's purposes.

\section{MEASURES}

To conduct the study, the following research methods were used:

Demographic questionnaire collecting necessary information on studied individuals, such as age, sex, type of illness, overall health, education, and domicile.

The Acceptance of Illness Scale (AIS). The AIS, developed by Felton et al. (1984), is used to assess the adjustment of an individual to their illness. The higher the acceptance, the lesser the extent of negative emotions experienced. The scale consists of 8 statements. The studied individual provides their responses determining their current state on a 5-step scale from 1 (I definitely agree) to 5 (I definitely do not agree). The Polish version of the scale was prepared by Juczyński (2012). The scale has a satisfactory level of reliability $(\alpha=.82)$. 


\section{Table 1}

Characteristics of participants

\begin{tabular}{|c|c|c|c|c|}
\hline Characteristics & $\operatorname{IBD}(N=159)$ & $\mathrm{UC}(n=107)$ & $\mathrm{CD}(n=52)$ & $p$ \\
\hline \multicolumn{5}{|l|}{ Sociodemographic } \\
\hline Age, $n(\%)$ & & & & .272 \\
\hline $18-25$ & $39(25)$ & $24(22)$ & $15(29)$ & \\
\hline $26-35$ & $64(40)$ & $43(40)$ & $21(40)$ & \\
\hline $36-45$ & $36(23)$ & $28(26)$ & $8(15)$ & \\
\hline $46-55$ & $13(8)$ & $6(6)$ & $7(14)$ & \\
\hline $56-65$ & $5(3)$ & $4(4)$ & $1(2)$ & \\
\hline Above 65 & $2(1)$ & $2(2)$ & - & \\
\hline Gender, $n(\%)$ & & & & .076 \\
\hline Female & $104(65)$ & $65(61)$ & $39(75)$ & \\
\hline Male & $55(35)$ & $42(39)$ & $13(25)$ & \\
\hline Education, $n(\%)$ & & & & .051 \\
\hline Primary & $3(2)$ & - & $3(6)$ & \\
\hline Lower secondary & $3(2)$ & $2(2)$ & $1(2)$ & \\
\hline Basic & $10(6)$ & $9(8)$ & $1(2)$ & \\
\hline Secondary & $47(30)$ & $29(27)$ & $18(35)$ & \\
\hline Higher & $96(60)$ & $67(63)$ & $29(56)$ & \\
\hline Location, $n(\%)$ & & & & .157 \\
\hline Countryside & $2(15)$ & $14(13)$ & $10(19)$ & \\
\hline City up to 50,000 inhabitants & $29(18)$ & $16(15)$ & $13(25)$ & \\
\hline City up to 250,000 inhabitants & $37(23)$ & $25(23)$ & $12(23)$ & \\
\hline City up to 500,000 inhabitants & $22(14)$ & $19(18)$ & $3(6)$ & \\
\hline City with more than 500,000 inhabitants & $47(30)$ & $33(31)$ & $14(27)$ & \\
\hline \multicolumn{5}{|l|}{ Clinical characteristics } \\
\hline Illness duration, $n(\%)$ & & & & .405 \\
\hline $1-5$ years & $72(45)$ & $51(48)$ & $21(40)$ & \\
\hline 6-10 years & $45(28)$ & $31(29)$ & $14(27)$ & \\
\hline $11-15$ years & $24(15)$ & $16(15)$ & $8(15)$ & \\
\hline More than 15 years & $18(11)$ & $9(8)$ & $9(17)$ & \\
\hline Health, $n(\%)$ & & & & .784 \\
\hline Remission & $85(53)$ & $58(54)$ & $27(52)$ & \\
\hline Exacerbation & $74(47)$ & $49(56)$ & $25(48)$ & \\
\hline Additional diseases & & & & .468 \\
\hline Yes & $76(48)$ & $49(46)$ & $27(52)$ & \\
\hline No & $83(52)$ & $58(54)$ & $25(48)$ & \\
\hline
\end{tabular}


Table 1

Table 1 continued

\begin{tabular}{|c|c|c|c|c|}
\hline Characteristics & $\operatorname{IBD}(N=159)$ & UC $(n=107)$ & $\mathrm{CD}(n=52)$ & $p$ \\
\hline \multicolumn{5}{|l|}{ Psychological characteristics } \\
\hline Type D $(M, S D)$ & $25.35(9.43)$ & $25.28(9.38)$ & $25.48(9.61)$ & .900 \\
\hline Negative affectivity $(M, S D)$ & $13.09(6.27)$ & $13.12(6.30)$ & $13.03(6.28)$ & .938 \\
\hline Social inhibition $(M, S D)$ & $13.12(4.08)$ & $13.09(3.89)$ & $13.17(4.49)$ & .909 \\
\hline Illness acceptance $(M, S D)$ & $24.75(8.57)$ & $24.75(8.44)$ & $24.77(8.90)$ & .988 \\
\hline Self-esteem $(M, S D)$ & $28.46(7.29)$ & $28.32(7.08)$ & $28.75(7.75)$ & .727 \\
\hline
\end{tabular}

The Personality Type D Scale (DS14). The DS14, developed by Denollet (2005), is used to measure stress personality. It contains 14 statements, 7 of which measure the tendency to experience negative emotions, thus creating the first dimension - negative affectivity $(\alpha=.86)$. The remaining 7 statements measure the reverse tendency to abstain from such emotions, thus creating the second dimension - social inhibition $(\alpha=.84)$. The studied individual answers the statements using a 5-step scale. The Polish version of this tool was prepared by Ogińska-Bulik et al. (2012).

Rosenberg Self-Esteem Scale (SES). The SES, developed by Rosenberg (1965), is used to measure the overall level of self-esteem. The studied individuals, who complete the scale, need to state whether they agree or disagree with each of the ten statements by providing answers on a 4-step scale from 1 (I definitely agree) to 4 (I definitely do not agree). The Polish version of the scale was prepared by Łaguna et al. (2007). The scale has a high level of reliability $(\alpha=.83)$.

\section{STATISTICAL ANALYSES}

Statistical analyses were performed using SPSS 26. Normality assessment was performed using the Kolmogorov-Smirnov test, homogeneity of variance was assessed with Levene's test. In the case of analyzed variables, the results permitted the use of parametric tests. The chi-squared test was used for categorical variables and the $t$-test for independent samples for continuous variables in normal distribution to assess differences between them. To calculate the effect size, Cohen's $d$ index was used. According to the classification proposed by Cohen (1992), we adopted the following assumptions to measure effect size: small effect $d=0.20$, medium effect $d=0.50$, large effect $d=0.80$. Analysis of correlations of analyzed variables was conducted using Pearson's correlation coefficient. The mediation analysis was performed using Macro Hayes' PROCESS (model 4) using 95\% confidence intervals yielded from 5,000 bootstrapped regression (Hayes, 2012).

\section{RESULTS}

The analysis conducted using Student's $t$-test for independent variables showed statistically significant differences between type D personality and self-esteem $(t=9.91, p<.001$, Cohen's $d=1.58)$. People with high self-esteem $(M=19.98, S D=6.67)$ were characterized by a lower type $\mathrm{D}$ personality than people with low self-esteem $(M=31.67, S D=8.22)$. The effect obtained proved to be large.

The analysis conducted using Student's $t$-test for independent variables also showed that type D personality is associated with illness acceptance $(t=4.34$, $p<.001$, Cohen's $d=0.69)$. The results showed that people with high acceptance $(M=22.13, S D=8.60)$ were characterized by lower type $\mathrm{D}$ personality than those who show low acceptance of illness $(M=28.29$, $S D=9.23)$. The obtained effect proved to be medium. This points to a significant association between type $\mathrm{D}$ personality, self-esteem, and acceptance of illness.

The proclivity to stress personality in the individuals was assessed next. According to criteria developed by Denollet for DS14 (Juczyński \& Ogińska-Bulik, 2012), type D comprises two separate dimensions - negative affectivity and social inhibition. Drawing conclusions regarding a tendency towards type D personality is possible if an individual obtains at least 10 points separately for each of those dimensions. Further analyses commenced with ascertaining the values of the two dimensions for each of the participants. Out of 159 individuals, 94 were included in further tests, as those individuals did obtain over 10 points for both dimensions of type $\mathrm{D}$ personality (Table 2). 
Table 2

Type D personality and its two dimensions - social inhibition and negative affectivity - in patients with CD and $U C$

\begin{tabular}{lcccccc}
\hline & \multicolumn{2}{c}{ Type D personality } & \multicolumn{2}{c}{ Negative affectivity } & \multicolumn{2}{c}{ Social inhibition } \\
\hline Disease & $<10$ & $>10$ & $<10$ & $>10$ & $<10$ & $>10$ \\
CD $(n=52)$ & $25(48 \%)$ & $27(52 \%)$ & $17(33 \%)$ & $35(67 \%)$ & $11(21 \%)$ & $41(79 \%)$ \\
UC $(n=107)$ & $40(37 \%)$ & $67(63 \%)$ & $34(32 \%)$ & $73(68 \%)$ & $21(20 \%)$ & $86(80 \%)$ \\
\hline
\end{tabular}

Note. CD - Crohn's disease; UC - ulcerative colitis.

\section{Table 3}

Correlations (Cronbach's coefficient $\alpha$ ) between variables: acceptance of illness, self-esteem, type D personality, negative affectivity, social inhibition $(N=94)$

\begin{tabular}{lccccrrr}
\hline & $M$ & $S D$ & 1 & 2 & 3 & 4 & 5 \\
\hline Acceptance of illness & 22.95 & 8.13 & 1 & $.44^{* * *}$ & $-.26^{*}$ & $-.27^{* *}$ & -.13 \\
Self-esteem & 25.20 & 6.02 & & 1 & $-.52^{* * *}$ & $-.61^{* * *}$ & -.17 \\
Type D personality & 32.14 & 6.55 & & & 1 & $.90^{*}$ & $.75^{* * *}$ \\
Negative affectivity & 16.90 & 4.72 & & & & 1 & $.38^{* * *}$ \\
Social inhibition & 15.23 & 3.07 & & & & & 1 \\
\hline
\end{tabular}

Note. ${ }^{*} p<.05,{ }^{* *} p<.01,{ }^{* * *} p<.001$

Type D personality was displayed by $52 \%$ of patients with Crohn's disease and 63\% of patients with ulcerative colitis. High levels of the first dimension (> 10) of type D personality - negative affectivity were displayed by $67 \%$ of patients with Crohn's disease and $68 \%$ of patients with ulcerative colitis. High levels of the second dimension $(>10)$ - social inhibition - were displayed by $79 \%$ of people with $\mathrm{CD}$ and $80 \%$ with UC.

The average standard deviation and correlation coefficients of all analyzed elements are presented in Table 3. A positive correlation between self-esteem and illness acceptance was confirmed. Additionally, a negative correlation of self-esteem with type $\mathrm{D}$ personality and negative affectivity, and of illness acceptance with type $\mathrm{D}$ personality and negative affectivity, was also confirmed. Sociodemographic data did not statistically significantly affect the investigated variables. All average values obtained for the analyzed variables may be accepted as satisfactory. They point to the studied individuals' tendency towards type $\mathrm{D}$ personality, and tendency to accept the illness and manifest self-esteem.

The analyses were then repeated for $N=94$ individuals. The analysis conducted using Student's $t$-test for independent variables showed statistically significant differences between type $\mathrm{D}$ personality and self-esteem $(t=4.10, p<.001$, Cohen's $d=0.85)$. People with high self-esteem $(M=29.52, S D=5.39)$ were characterized by a lower type $\mathrm{D}$ personality than people with low self-esteem $(M=34.65, S D=6.63)$. The observed effect size was large.

The analysis conducted using Student's $t$-test for independent variables also showed that type $\mathrm{D}$ personality is related to illness acceptance $(t=2.09, p<.05$, Cohen's $d=0.43)$. The results have showed that people with high acceptance $(M=30.66, S D=6.05)$ were characterized by lower type $\mathrm{D}$ personality than those with low acceptance of illness $(M=33.44, S D=6.76)$. The observed effect size was small. This points to a strong connection between type D personality, selfesteem, and acceptance of illness.

The analysis showed statistically significant differences between the first dimension of type $D$ personality - negative affectivity - and self-esteem $(t=5.03$, $p<.001$, Cohen's $d=1.38$ ). People with high selfesteem $(M=14.67, S D=3.60)$ were characterized by a lower type of negative affectivity than people with low self-esteem $(M=19.04, S D=4.72)$. The effect size was large. Moreover, the analysis showed that negative affectivity is related to illness acceptance $(t=2.04$, $p<.05$, Cohen's $d=0.42$ ). The results showed that people with high acceptance $(M=15.86, S D=4.52)$ were characterized by lower negative affectivity than those with low acceptance of illness $(M=17.82$, $S D=4.76)$. The effect size was small. However, the analysis between the second dimension of type $\mathrm{D}$ personality - social inhibition - and self-esteem $(t=1.20$, 
$p=.235)$ and between social inhibition and illness acceptance $(t=1.30, p=.195)$ did not reveal statistically significant differences.

A mediation analysis was then conducted, with two dimensions of stress personality: negative affectivity and social inhibition as independent variables, the dependent variable was the acceptance of illness, and the mediator was self-esteem. Mediation analysis was conducted using the 4 Hayes model. Similar analysis was conducted for type D personality as one factor.

In the case of the first dimension of type $\mathrm{D}$ personality, negative affectivity was an important prognostic factor for self-esteem, $B=-.77, S E=.11,95 \% \mathrm{CI}$ $[-.98,-.56], \beta=-.61, p=.001$ and self-esteem was an important prognostic factor for illness acceptance, $B=.58, S E=.16,95 \%$ CI $[.26, .90], \beta=.43, p=.001$. Negative affectivity was also an important predictor of illness acceptance, $B=-.47, S E=.17,95 \% \mathrm{CI}[-.81$, $-.13], \beta=-.13, p=.001$. Negative affectivity was not a significant predictive factor after controlling for the mediator, $B=-.02, S E=.20,95 \% \mathrm{CI}[-.43, .38], \beta=.43$, $p=.914$. This result suggested the full mediating effect on the relationship between a D-type personality and acceptance of illness. These results indicated that the indirect coefficient was significant, $B=-.45$, $S E=.14,95 \%$ CI $[-.74,-.19]$, partially standardized $\beta=-.05$. The model of regression with the mediator (self-esteem) allowed a larger amount of variance in illness acceptance (19\%) to be explained than the model only taking into consideration the negative affectivity (3\%).

In the case of the second dimension, social inhibition was not an important prognostic factor for selfesteem, $B=-.33, S E=.20,95 \%$ CI $[-.73, .07], \beta=-.16$, $p=.108$. Self-esteem was an important prognostic factor for illness acceptance, $B=.57, S E=.13,95 \% \mathrm{CI}$ $[.32, .83], \beta=.43, p=.001$. Social inhibition was also not an important predictor of illness acceptance, $B=-.34, S E=.27,95 \%$ CI $[-.89, .20], \beta=-.13, p=.213$, and was not a significant predictive factor after controlling for the mediator, $B=-.16, S E=.25,95 \% \mathrm{CI}$ $[-.66, .35], \beta=-.05, p=.541$. The conducted mediation analysis showed that self-esteem does not have a mediating role between the second dimension of stress personality - social inhibition - and acceptance of illness.

In the final step we verified whether self-esteem acts as a mediator between type D personality, composed of both dimensions (negative affectivity and social inhibition) and acceptance of illness. Type D personality was an important prognostic factor for self-esteem, $B=-.47, S E=.08,95 \%$ CI $[-.64,-.31]$, $\beta=-.52, p=.001$, and self-esteem was an important prognostic factor for illness acceptance, $B=.56$, $S E=.15,95 \%$ CI $[.26, .85], \beta=.41, p=.001$. Type D personality was also an important predictor of illness acceptance, $B=-.32, S E=.13,95 \%$ CI $[-.57,-.07]$,

\section{Figure 1}

Conceptual diagram of model 4 Hayes

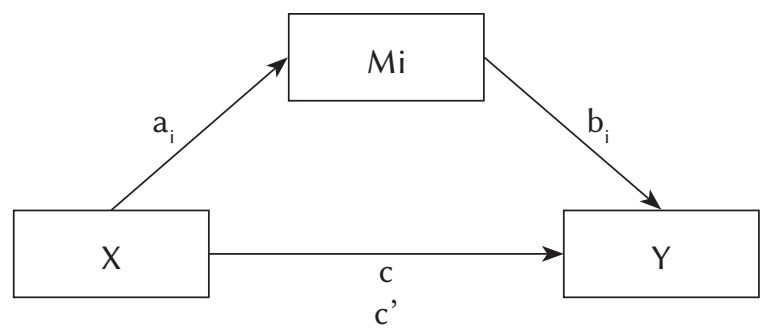

Note. $\mathrm{X}=$ independent variable, $\mathrm{Y}=$ dependent variable; $M=$ mediator, indirect effect of $X$ on $Y$ through $M i=a_{i} b_{i}$; direct effect of $\mathrm{X}$ on $\mathrm{Y}$ after mediator $=\mathrm{c}^{\text {'; }}$; direct effect of $\mathrm{X}$ on $\mathrm{Y}$ before mediator $=\mathrm{c}$.

$\beta=-.26, p=.012$. Type $\mathrm{D}$ personality was not a significant predictive factor after controlling for the mediator, $B=-.06, S E=.14,95 \% \mathrm{CI}[-.33, .22], \beta=-.04$, $p=.544$. Approximately $19 \%$ of the variance in acceptance of illness was accounted for by the predictors. These results indicated that the indirect coefficient was significant, $B=-.26, S E=.08,95 \% \mathrm{CI}[-.44,-.11]$, partially standardized $\beta=.03$. This result suggested the full mediator effect on the relationship between a D-type personality and acceptance of illness.

\section{DISCUSSION}

The study's purpose was to confirm whether self-esteem acts as a mediator in the relationship between type D personality and illness acceptance. The results confirmed the previous assumptions regarding a positive correlation between self-esteem and illness acceptance (Juczyński, 2012). Moreover, the results showed that individuals with type D personality display lower levels of self-esteem than those without type D personality. The results of this study confirmed previous analyses (Denollet, 1998; Watson \& Pennebaker, 1989). It is worth adding, however, that still not much is known about the presumed mechanisms that generate lower self-esteem when type D personality is present. One potential explanation may refer to negative affectivity, which shows similarities to traits characteristic of neuroticism. Neurotic individuals often display low self-esteem. Moreover, they are convinced of the lack of their effectiveness and are oversensitive to criticism or disapproval.

A conducted mediation analysis for the first dimension of type D personality - negative affectivity - showed that self-esteem is a complete mediator of the relationship between negative affectivity and acceptance of illness in individuals suffering from inflammatory bowel disease. The direct result of 
the independent variable and the dependent variable showed that the higher the intensity of negative affectivity is, the lower is the acceptance of illness. However, after adding the mediator, the relationship between negative affectivity and illness acceptance was no longer significant. Mediation analysis conducted between social inhibition and acceptance of illness did not confirm the mediating role of selfesteem.

The conducted mediation analyses indicated that self-esteem may play an important role in coping with experiencing and displaying negative emotions, such as anger or anxiety, characteristic of type D personality. However, it is not an important element in behaviors linked with social inhibition and limiting interpersonal contacts.

Studies have shown that self-esteem plays an important role in accepting illness in the case of studied individuals who tend towards type $\mathrm{D}$ personality. It seems justified, then, to pay close attention, during treatment, to whether patients display a tendency towards stress personality, as well as to their self-esteem (Goodhand \& Rampton, 2008; Opheim et al., 2020). Proclivity towards stress personality may cause intensification of symptoms, which will negatively affect acceptance of illness and the whole treatment. On the other hand, patients with bowel diseases often have - due to the experienced symptoms, disrupted body image, and the feeling of stigmatization - a lowered self-esteem, which is essential to the adjustment to the illness and its acceptance (Janke et al., 2005; Taft et al., 2009, 2011). Thus, during interventions, holistic actions of all people involved in the treatment need to be taken into consideration. This includes clinical psychologists, or psychotherapeutics, who can assess whether the patient displays traits characteristic of stress personality and the level of their self-esteem, and attending physicians and nurses, who could be the first to notice the typical symptoms (Fakhoury et al., 2014; Kiebles et al., 2010; Larsson et al., 2017; Pellissier et al., 2010).

Previous research on bowel disease has underscored the criticality of the stress factor as one of the key elements that negatively affect patients' health and exacerbate some symptoms (Mawdsley \& Rampton, 2006; Rampton, 2009). This is why more analyses are conducted to confirm the tendency for individuals suffering from bowel diseases to exhibit type D personality (Morys et al., 2016; Sajadinejad et al., 2012). The regression analysis with self-esteem as a mediator showed a significantly decreased direct association between negative affectivity and illness acceptance and between type D personality and acceptance, thus positively affecting the process of adjusting to the illness. It seems reasonable that patients suffering from bowel diseases should be provided with various forms of support to build and reinforce positive self-esteem, e.g., through the preparation of preventative programs or psychological therapy.

The results of the analyses may be important for a number of reasons. This is the first study known to us that analyses the role of self-esteem as a mediator between type $\mathrm{D}$ personality and acceptance of illness in individuals with bowel diseases. Therefore, it is a form of introduction to further analyses, focused more on the role of self-esteem in bowel diseases, and finding other relationship mediators between type D personality and acceptance of illness.

Secondly, acceptance of illness, especially in incurable, chronic diseases, plays a crucial role. It allows us to adjust to living with the disease and continuously cope with all the difficulties the patients need to face. In the case of patients with a proclivity towards type D personality, which is negatively correlated with acceptance of illness, the adjustment will be especially difficult, which may have severe consequences, such as an increased tendency to experience negative emotional states, including depression, social withdrawal, and loneliness, and holistically having a negative impact on the patients' quality of life.

Thus, knowing about such relationships may be important for developing better methods of intervention, such as training on building self-esteem for clinical psychologists and physicians working with patients with bowel diseases (Opheim et al., 2020).

This is the first study to explore possible mediators affecting the link between type D personality and acceptance of illness in people with inflammatory bowel disease, which means this study can be constricted by certain limitations, which should be considered when conducting future analyses. First, the study could be repeated on a larger group of patients, considering additional diagnostic criteria, such as the number of surgical procedures or pharmacological therapies taking place at the time of the study (Fakhoury et al., 2014). Second, it would be beneficial to consider a control group as well, meaning healthy individuals, and compare the intensity of stress personality in both the control and study group (Sajadinejad et al., 2012). Deepening the analyses on the self-esteem of people suffering from bowel diseases, such as what factors affect it, would also add an interesting aspect to the study (Opheim et al., 2020).

\section{ACKNOWLEDGMENTS}

In recruitment of study participants we were aided by: administrators of the Polish Association Supporting People with IBD and the social media portal J-elita, as well as the administrators of the Crohn \& Colitis - A Common Cause portal, for which we give our deepest thanks. 


\section{REFERENCES}

Basińska, M., \& Andruszkiewicz, A. (2016). Cechy osobowości typu D a funkcjonowanie w chorobie pacjentów z chorobami przewlekłymi [Type D personality traits and disease functioning in patients with chronic diseases]. Polskie Forum Psychologiczne, 22, 221-237.

Bisschop, M. I., Kriegsman, D. M. W., Beekman, A. T. F., \& Deeg, D. J. H. (2004). Chronic diseases and depression: The modifying role of psychosocial resources. Social Science \& Medicine, 59, 721-733. https://doi.org/10.1016/j.socscimed.2003.11.038

Byron, C., Cornally, N., Burton, A., \& Savage, E. (2020). Challenges of living with and managing inflammatory bowel disease: a meta-synthesis of patients' experiences. Journal of Clinical Nursing, 29, 305-319. https://doi.org/10.1111/jocn. 15080

Cohen, J. (1992). A power primer. Psychological Bulletin, 112, 155-159. https://doi.org/10.1037/00332909.112.1.155

Cybulski, M., Cybulski, L., Krajewska-Kulak, E., \& Cwalina, U. (2017). Illness acceptance, pain perception and expectations for physicians of the elderly in Poland. BMC Geriatrics, 17, 46. https://doi. org/10.1186/s12877-017-0441-4

Denollet, J. (1998). Personality and coronary heart disease: The Type-D Scale-16 (DS16). Annals of Behavioral Medicine, 20, 209-215. https://doi.org/10.1007/ BF02884962

Denollet, J. (2005). DS14: Standard assessment of negative affectivity, social inhibition, and type D personality. Psychosomatic Medicine, 67, 89-97. https:// doi.org/10.1097/01.psy.0000149256.81953.49

Fakhoury, M., Al-Salami, H., Negrulj, R., \& Mooranian, A. (2014). Inflammatory bowel disease: Clinical aspects and treatments. Journal of Inflammation Research, 7, 113-120. https://doi.org/10.2147/JIR.S65979

Felton, B. J., Revenson, T. A., \& Hinrichsen, G. A. (1984). Stress and coping in the explanation of psychological adjustment among chronically ill adults. Social Science \& Medicine, 18, 889-898. https://doi.org/10.1016/0277-9536(84)90158-8

Goodhand, J. R., Wahed, M., Mawdsley, J. E., Farmer, A. D., Aziz, Q., \& Rampton, D. S. (2012). Mood disorders in inflammatory bowel disease: Relation to diagnosis, disease activity, perceived stress, and other factors. Inflammatory Bowel Diseases, 18, 2301-2309. https://doi.org/10.1002/ibd.22916

Goodhand, J., \& Rampton, D. (2008). Psychological stress and coping in IBD. Gut, 57, 1345-1347. https://doi.org/10.1136/gut.2008.154229

Greenley, R. N., Hommel, K. A., Nebel, J., Raboin, T., Li, S. H., Simpson, P., \& Mackner, L. (2010). A meta-analytic review of the psychosocial adjustment of youth with inflammatory bowel disease. Journal of Pediatric Psychology, 35, 857-869. https:// doi.org/10.1093/jpepsy/jsp120
Hayes, A. F. (2012). PROCESS: a versatile computational tool for observed variable mediation, moderation, and conditional process modeling. Retrieved from http://www.afhayes.com/ public/process2012.pdf

Hogg, M. A., \& Vaughan, G. M. (2011). Self and identity. In G. M. Vaughan \& M. A. Hogg (Eds.), Social psychology (Vol. 6, pp. 111-146). NY Pearson Prentice Hall.

Huis in't Veld, E. M. J., Vingerhoets, A. J. J. M., \& Denollet, J. (2011). Attachment style and self-esteem: The mediating role of type D personality. Personality and Individual Differences, 50, 1099-1103. https://doi.org/10.1016/j.paid.2011.01.034

Janke, K. H., Klump, B., Gregor, M., Meisner, C., \& Haeuser, W. (2005). Determinants of life satisfaction in inflammatory bowel disease. Inflammatory Bowel Diseases, 11, 272-286. https://doi. org/10.1097/01.MIB.0000160809.38611.f7

Juczyński, Z. (2012). Narzędzia pomiaru w promocji i psychologii zdrowia [Measurement tools in health promotion and psychology]. Pracownia Testów Psychologicznych PTP.

Juczyński, Z., \& Ogińska-Bulik, N. (2012). Narzędzia pomiaru stresu i radzenia sobie ze stresem [Measurement tools in stress and coping tools]. Pracownia Testów Psychologicznych PTP.

Juth, V., Smyth, J. M., \& Santuzzi, A. M. (2008). How do you feel? Self-esteem predicts affect, stress, social interaction, and symptom severity during daily life in patients with chronic illness. Journal of Health Psychology, 13, 884-894. https://doi. org/10.1177/1359105308095062

Kiebles, J. L., Doerfler, B., \& Keefer, L. (2010). Preliminary evidence supporting a framework of psychological adjustment to inflammatory bowel disease. Inflammatory Bowel Diseases, 16, 1685-1695. https://doi.org/10.1002/ibd.21215

Krajewski, W., Mazur, M., Poterek, A., Pastuszak, A., Halska, U., Tukiendorf, A., Rymaszewska, J., \& Zdrojowy, R. (2018). Assessment of pain management, acceptance of illness, and adjustment to life with cancer in patients with nonmuscle invasive bladder cancer. BioMed Research International, 2018, 7598632. https://doi.org/10.1155/2018/ 7598632

Larsson, K., Lööf, L., \& Nordin, K. (2017). Stress, coping and support needs of patients with ulcerative colitis or Crohn's disease: a qualitative descriptive study. Journal of Clinical Nursing, 26, 648-657. https://doi.org/10.1111/jocn.13581

Łaguna, M., Lachowicz-Tabaczek, K., \& Dzwonkowska, I. (2007). Skala samooceny SES Morrisa Rosenberga - polska adaptacja metody [Rosenberg Self-Esteem Scale: Polish adaptation of the scale] Psychologia Spoteczna, 2, 164-176.

Maunder, R. G., \& Levenstein, S. (2008). The role of stress in the development and clinical course of inflammatory bowel disease: Epidemiological 
evidence. Current Molecular Medicine, 8, 247-252. https://doi.org/10.2174/156652408784533832

Mawdsley, J. E., \& Rampton, D. S. (2006). The role of psychological stress in inflammatory bowel disease. Neuroimmunomodulation, 13, 327-336. https://doi.org/10.1159/000104861

McDermott, E., Mullen, G., Moloney, J., Keegan, D., Byrne, K., Doherty, G. A., Cullen, G., Malone, K., \& Mulcahy, H. E. (2015). Body image dissatisfaction: Clinical features, and psychosocial disability in inflammatory bowel disease. Inflammatory Bowel Diseases, 21, 353-360. https://doi.org/10.1097/ MIB.0000000000000287

Moreno-Jiménez, B., López Blanco, B., RodríguezMuñoz, A., \& Garrosa Hernández, E. (2007). The influence of personality factors on health-related quality of life of patients with inflammatory bowel disease. Journal of Psychosomatic Research, 62, 3946. https://doi.org/10.1016/j.jpsychores.2006.07.026

Morys, J. M., Kaczówka, A., \& Jeżewska, M. (2016). Assessment of selected psychological factors in patients with inflammatory bowel disease. Gastroenterology Review, 1, 47-53. https://doi.org/10.5114/ pg.2015.52560

Moss-Morris, R. (2013). Adjusting to chronic illness: Time for a unified theory. British Journal of Health Psychology, 18, 681-686. https://doi.org/10.1111/ bjhp. 12072

Ogińska-Bulik, N. (2009). Osobowość typu D - teoria i badania [Type D personality - theory and research]. WSHE.

Ogińska-Bulik, N., Juczyński, Z., \& Denollet, J. (2012). DS14 - skala do pomiaru typu D [DS14 - scale for measurement type D]. In Z. Juczyński \& N. Ogińska-Bulik (Eds.), Narzędzia pomiaru stresu i radzenia sobie ze stresem [Measurement tools in stress and coping tools] (pp. 71-85). Pracownia Testów Psychologicznych PTP.

Opheim, R., Moum, B., Grimstad, B. T., Jahnsen, J., Prytz Berset, I., Hovde, Ø., Huppertz-Hauss, G., Bernklev, T., \& Jelsness-Jørgensen, L. P. (2020). Self-esteem in patients with inflammatory bowel disease. Quality of Life Research, 29, 1839-1846. https://doi.org/10.1007/s11136-020-02467-9

Pellissier, S., Dantzer, C., Canini, F., Mathieu, N., \& Bonaz, B. (2010). Psychological adjustment and autonomic disturbances in inflammatory bowel diseases and irritable bowel syndrome. Psychoneuroendocrinology, 35, 653-662. https://doi.org/ 10.1016/j.psyneuen.2009.10.004

Polak, E. J., O'Callaghan, F., \& Oaten, M. (2020). Perceptions of IBD within patient and community samples: a systematic review. Psychology \& Health, 35, 425-448. https://doi.org/10.1080/088 70446.2019.1662014

Rampton, D. (2009). Does stress influence inflammatory bowel disease? The clinical data. Digestive Diseases, 27, 76-79. https://doi.org/10.1159/000268124
Rosenberg, M. (1965). Society and the adolescent selfimage. Princeton University Press.

Sajadinejad, M. S., Molavi, H., Asgari, K., Kalantari, M., \& Adibi, P. (2012). Personality dimensions and type $D$ personality in female patients with ulcerative colitis. Journal of Research in Medical Sciences, 17, 898-904.

Sgambato, D., Miranda, A., Ranaldo, R., Federico, A., \& Romano, M. (2017). The role of stress in inflammatory bowel diseases. Current Pharmaceutical Design, 23, 3997-4002. https://doi.org/10.2174/138 1612823666170228123357

Taft, T. H., Keefer, L., Artz, C., Bratten, J., \& Jones, M. P. (2011). Perceptions of illness stigma in patients with inflammatory bowel disease and irritable bowel syndrome. Quality of Life Research, 20, 13911399. https://doi.org/10.1007/s11136-011-9883-x

Taft, T. H., Keefer, L., Leonhard, C., \& NealonWoods, M. (2009). Impact of perceived stigma on inflammatory bowel disease patient outcomes. Inflammatory Bowel Diseases, 15, 1224-1232. https:// doi.org/10.1002/ibd.20864

Telford, K., Kralik, D., \& Koch, T. (2006). Acceptance and denial: Implications for people adapting to chronic illness - literature review. Journal of Advanced Nursing, 55, 457-464. https://doi.org/10.1111/j.13652648.2006.03942.x

Triantafillidis, J. K., Merikas, E., \& Gikas, A. (2013). Psychological factors and stress in inflammatory bowel disease. Expert Review of Gastroenterology \& Hepatology, 7, 225-238. https://doi.org/10.1586/ egh.13.4

Watson, D., \& Pennebaker, J. W. (1989). Health complaints, stress, and distress: Exploring the central role of negative affectivity. Psychological Review, 96, 234-254. https://doi.org/10.1037/0033-295x.96.2.234 